\title{
EFFECT OF PHYSIOCHEMICAL FACTORS ON FRUITING BODY FORMATION IN MUSHROOM
}

\author{
FOZIYA KHAN*, RAMESH CHANDRA
}

Department of Bio-Engineering, Birla Institute of Technology, Mesra-835215, Ranchi, India

Email: foziya.khan1987@gmail.com

Received: 18 May 2017 Revised and Accepted: 31 Aug 2017

\begin{abstract}
Objective: Fungi are heterotrophs and are involved in decomposition, nutrient cycling and nutrient transport, and are indispensable for achieving sustainable development. Mushrooms are the fungi with a distinctive fruiting body. Mushrooms are produced all over the world. In India, Punjab is the leading mushroom growing state. Mushrooms are rich sources of proteins, vitamins and minerals. Different types of immunoceuticals like lentinan, schizophyllan, active hexose correlated compound (AHCC) etc. have also been prepared from various mushrooms. The present review work highlights important observations in the area of mushroom.
\end{abstract}

Methods: This review also shows that how several factors affect the fruiting body formation of mushrooms, which includes physiological (composition of culture media) and environmental factors (light, temperature, salinity, etc.). There are different factors like light, temperature etc. which affects the fruiting body development.

Results: It has been found that, light has positive effects on hyphal aggregation and fruiting body maturation. It has been found that in oyster mushroom, light is essential for both normal expansion of pileus and in spore formation. It has been found that length of Stipe and the diameter of cap decreases with an increase in the concentration of $\mathrm{CO}_{2}$. Also, there is a range of temperature within which sporophore development occurs. The composition of media affects the growth of mushrooms too. It's important to maintain a balance between carbon and nitrogen sources for induction of the fruiting body.

Conclusion: There are different environmental factors affecting the fruiting body development of mushrooms. Hence, by adjusting various factors like temperature, light, media composition production of mushrooms can be increased.

Keywords: Hyphal aggregation, Fruiting body, Culture, Media, Mushroom

(C) 2017 The Authors. Published by Innovare Academic Sciences Pvt Ltd. This is an open-access article under the CC BY license (http://creativecommons.org/licenses/by/4.0/) DOI: http://dx.doi.org/10.22159/ijpps.2017v9i10.20086

\section{INTRODUCTION}

The fungus is the second most diverse of all groups and has been considered as a prime member of the other mega-diverse groups comprising of insects, bacteria, arachnids and nematodes [1]. The kingdom fungi include yeasts, molds, smuts, and mushrooms. The size ranges from a single-celled organism such as yeast to the largest known living organism on earth - a 3.5-mile-wide mushroom. The spores are produced on the gills on the underside of the cap, and a stipe carries the fruit body above the ground to promote spore distribution by air currents. Spores develop on specialized cells, i.e. basidia in the Basidiomycetes or in a sac-like structure called ascus in Ascomycetes [2].

Mushroom is a macrofungus with a distinguishing fruiting body. It can be both epigenous and hypogenous and are easily visible with the naked eye and can be picked up by hand [3]. Mushrooms are the richest source of proteins, vitamins and minerals and are low in fat content (2-8\%) and their unique chemical constitution makes them low-calorie food and choice diet for those suffering from hypertension, atherosclerosis, diabetes, obesity, etc. Mushrooms usually contain $19-35 \%$ protein. A protein present in mushroom contains all the necessary amino acids and are particularly high in lysine and leucine content, which are usually absent in many cereal foods. Because of the less amount of total fat and a large amount of polyunsaturated fatty acids (72-85\%) compared with total fatty acids, a mushroom is found to be a healthy diet. The digestibility of mushroom protein ranges between 71-90\%. Presence of tryptophan and lysine in mushroom protein make it a better substitute for animal protein. In some edible mushrooms, the percentage of protein quality varies [4]. Mushrooms are an excellent source of riboflavin and nicotinic acid. They also contain niacin and are a good source of pantothenic acid. An appreciable amount of thiamin, folic acid, and ascorbic acid is also present [5]. In Lentinula edodes (Shiitake mushroom) concentration of thiamine, riboflavin and niacin are 7.8, 4.9 and $54.9(\mathrm{mg} / 100 \mathrm{gm})$ [6]. In Volvariella volvacea concentration of thiamine, riboflavin and niacin are $0.35,2.97$ and $64.88(\mathrm{mg} / 100 \mathrm{gm})[6]$. Also, the wild mushroom especially Lentinus fusipes and Lentinus tuberigium were found to be rich in the amount of iron and calcium, along with having useful phytochemicals such as phenolics, ascorbic acid, carotenoids [7]. These values are on the basis of the dry weight of mushrooms.

Potential immunoceuticals have been produced from more than 50 mushroom species that show anticancer activity in vitro and in animal models. Among all these polysaccharides, six have been found in human cancers, including lentinan, schizophyllan, active hexose correlated compound (AHCC), maitake D-fraction, polysaccharide- $\mathrm{K}$ and polysaccharide-P [8]. Immunoceuticals isolated from more than 30 mushroom species have shown anticancer properties in animals, but only a few have been involved in human cancer research [9]. Combination of naturally occurring purified carbohydrates from $P$. florida and most common drug used in glioblastoma treatment named temozolomide (TMZ) increases the efficacy of the drug by enhancing its anti-cancer properties, such as cellular cytotoxicity, cell cycle arrest and higher expression of p53 significantly in Glioblastoma cell lines. As both mannitol and glucose have excellent cell permeability properties, improving the access and half-life of TMZ would promote a greater accumulation of TMZ within cells. Such permeation could increase drug uptake ability of cells, which finally shows increased therapeutic impact. Therefore, the drug would be more effective and lower doses could be used in current therapeutic management strategies. This would lead to the treatment of glioblastomas more effective and less expensive, with reduced side effects, hence improving prognosis [10].

The demand for mushroom has been on the rise because of increased detection of mushroom medicinal and nutritional values, together with the recognition of the income generating the fungi potential through trade. The edibility of mushrooms depends upon 
the absence of toxin content and its desirable taste and aroma. Mushrooms are getting popular among health-conscious consumers because it is very rich in nutrients and also there is no fat, cholesterol, and gluten and a very less amount of sodium. In 2013, mushrooms global market was estimated at $\$ 29,427.92$ million. This mushroom market is predicted to grow at a CAGR of 9.5\% from 2014 to achieve $\$ 50,034.12$ million by 2019 . In 2013 , the market was dominated by the Europe and is expected to be the greatestdeveloping market for mushrooms during the year 2014 and 2019, followed by the Asia-Pacific region [11].

There are a total 2,300 species of edible and medicinal fungi. Cultivated mushrooms are now famous in the world with more than 200 genera of useful macrofungi. Agaricus bisporus (button mushrooms), Lentinula edodes (shiitake mushrooms) and Pleurotus spp. (oyster mushrooms) are most commonly produced and consumed. In 2013 this accounted for approximately $76 \%$ of the mushroom market size globally [10]. In 2013, the contribution of the button mushrooms segment was nearly $36.1 \%$ of the entire mushroom market. A major role in mushroom production is found in white button mushroom in the U. S. and Europe [11].

Common problems associated with fruiting body formation in India and third world mushroom industries are inadequate scientific and technical knowledge regarding mushroom cultivation, lack of trained personnel, mushroom cultivation in the unorganized sector, wastage of produced mushrooms, loss of resources and lack of knowledge regarding the physiology of fruiting body formation.

The present paper aims for compiling and reviewing the information available in the area of physiology of fruiting body formation in mushrooms.

\section{MATERIALS AND METHODS}

\section{Search strategy for the present studies}

Several research papers, review papers, articles and proceedings on mushrooms were searched till May 2017. Searches were restricted to the English language only and were limited by the period up to June 2016.

\section{RESULTS AND DISCUSSION}

Physio-chemical factors affecting fruiting body formation of the mushroom

\section{Environmental effect on fruiting body development}

In making a decision regarding the fruiting body formation, environmental factors play a vital role. The ideal environmental condition for the growth of mycelia and later on fruiting is normally different. Development of fruiting body commonly happens after severely changing the environmental circumstances [12]. Vegetative mycelium is generally produced over a broad range of temperatures. Similarly, the formation of knots in hyphae and the stages in the formation of primordia might not be restricted to a particular temperature, even though these types of developments are normally preferred at definite temperatures [12-15]. For ectomycorrhizal fungi under artificial conditions, it's not surprising that the occurrence of a symbiotic plant may permit the successful formation of the fruiting body [16-17].

The sensing of environmental conditions has been used to regulate fruiting body formation in Agaricus bisporus where a change of vegetative phase to initiation of the fruiting body was noticed. A model has been proposed in which three different environmental factors control various stages of the reproductive developmental process. Early differentiation of the vegetative hyphae to multicellular knots is regulated by the eight carbon volatile compound 1-octen-3-ol. For the later differentiation of primordia, temperature reduction is essential. Also, carbon dioxide level quantitatively controls the number of fruiting bodies developed [18].

\section{Factors regulating fruiting body development}

1. Light: Intensity, duration, and wavelength of light are vital components of any treatment. Normally, light positively affects both aggregation of hyphae and maturation of the fruiting body, but, on the contrary, the formation of the hyphal knot can be suppressed by the light. When lighting is too strong or too long, stages in the development of fruiting body are hampered too. A small light pulse of low energy is sufficient to initiate aggregation in hyphae [19]. The positioning of the stipe and pileus of oyster mushroom has been shown to be controlled by the phototropic responses. Not only light is required for the normal expansion of the pileus but also phototropism plays a prominent role in spore formation [20]. The light requirements are different for various stages of growth. Mycelium growth doesn't need light. The formation of primordia requires light of 200lux intensity for about $12 \mathrm{~h}$ a day. The growth of the fruiting body requires light of 50-500lux intensity [20].

2. $\mathrm{CO}_{2}$ concentration: The $\mathrm{CO}_{2}$ content of the atmosphere may have an intense impact on sporophore development. Higher $\mathrm{CO}_{2}$ concentrations may activate growth of mycelia and prevent fruiting completely. Fruiting bodies might get deformed at lower $\mathrm{CO}_{2}$ concentrations, with lengthened stipes and reduced pilei $[12,13,21$, 22]. In Agaricus bisporus the concentration of $\mathrm{CO}_{2}$ in the substratum of commercial compost beds, rarely falls below $0.3 \%$, about ten times the normal atmospheric concentrations, and may rise to $20 \%$ or higher during the growth of the mycelium. Concentrations above 1-5\% activate stipe elongation but prevented cap expansion. Normal sporophore development occurs at about $0.2 \% \mathrm{CO}_{2}$ [23].

Table 1: Fruiting body shape at different $\mathrm{CO}_{2}$ concentration [23]

\begin{tabular}{lll}
\hline $\mathrm{CO}_{2}$ concentration (\%) & Diameter of cap(mm) & Length of stipe(mm) \\
\hline 0.03 & 6.5 & 4.6 \\
0.1 & 3.4 & 6.8 \\
0.3 & 2.4 & 6.7 \\
0.5 & 0.6 & 2.5 \\
\hline
\end{tabular}

3. Humidity and evaporation: For pinning and fruiting, high humidity $(90-95 \%)$ is advantageous, but the substrate moisture content might be even more critical $[13,15,21]$.

4. Temperature: There is usually a range of temperature within which sporophore development occurs. The increase of temperature within the lower part of this range hinders development. By decreasing the temperature by at least $5^{\circ} \mathrm{C}$, after vegetative growth fruiting is generally induced, for example, in $A$. bisporus to $16-18^{\circ} \mathrm{C}$, in C. cinereus to $25-28^{\circ} \mathrm{C}$ and in, $F$. velutipes to $18^{\circ} \mathrm{C}[12,13,15]$. For $C$. cinereus the optimum temperature for mycelial growth is about $37^{\circ} \mathrm{C}$ but fruit bodies are not formed above $30^{\circ} \mathrm{C}$. At each temperature tested, the growth of the mycelium of mushroom Pleurotus ostreatus was notably faster than mushroom Pleurotus cystidiosus. Pleurotus cystidiosus didn't grow beyond $8 \mathrm{~d}$ of inoculation maintained at $36^{\circ} \mathrm{C}$. In Pleurotus cystidiosus the density of mycelium was very thin at $16^{\circ} \mathrm{C}$ and $36^{\circ} \mathrm{C}$. This ideal temperature effect showed that the two species of oyster mushroom Pleurotus ostreatus and Pleurotus cystidiosus were capable to grow better in summer and autumn season in subtropical and tropical regions. In deprived and rising countries in Asia to enhance the production of oyster mushroom, it provides a potential opportunity [24].

5. Salinity and pH: For growth, basidiomycetes tolerate a comparatively large amount of salts, yet the development of fruiting body could be more susceptible. Similarly, development of mycelia is moderately affected by $\mathrm{pH}$, but the development of a fruiting body of various species is found to be best at neutral or somewhat acidic $\mathrm{pH}$ values nearly 6-7 [13,21] or in L. edodes at a pH of 4.0 [25]. 
6. Microorganisms: Presence of some organisms also affect fruiting of some saprophytic species. There are many Agaricus strains fruiting only when they are coupled with microorganisms like Pseudomonas. Experiments conducted with charcoal suggest that microorganisms influence fruiting process by removing inhibitory compounds rather than by producing induction substances [26]. Hyphal growth gets stimulated by some bacterial metabolites too. Like Streptomyces sp. AcH505, when associated with Amanita muscaria, shows an increased production of auxofuran, a secondary metabolite. This auxofuran promotes the expansion of the mycelium of the fungus [27]. In many bacterial-fungal interactions, diffusible molecules carries out an important role. Also, in the formation of bacterial-fungal interactions, processes like migration and physical contact are significant. Bacteria shows chemotaxis towards fungi and molecules derived from fungi. It has been proved in several instances that both detrimental and beneficial Pseudomonas sp. exhibit taxis towards fungal mycelial exudates [28-29].

7. Media components: Polymeric alkyl pyridinium salts are water soluble, surfactant-like compounds. They get purified in sufficient quantity from the marine sponge Reniera sarai. Poly-APS exhibits a wide range of biological activities, possibly due to their detergentlike properties like cytotoxic [30], hemolytic [31], anticholinesterase [32], antimicrobial [33], but, they are ineffective against fungal cells. The rate of mycelia growth of Pleurotus ostreatus mushroom in the growth medium does not get affected by adding poly-APS. However; it increased the primordial formation, which appeared $10 \mathrm{~d}$ earlier than in control experiments. All concentrations of poly-APS when tested raised the production of fruiting bodies, getting a peak at $1 \mathrm{mg} / \mathrm{ml}$. Instead, no primordia appeared on plates treated with either the fatty acids or the lysophospholipids. An inhibitory effect that is of concentrationdependent nature was exerted on the growth of mycelia of $P$. ostreatus by all fatty acids or the lysophospholipids at concentrations higher than $0.01 \%$. Thus, it can be concluded that poly-APS increases the process of fruiting and production of oyster mushrooms. As it has previously been reported for a few compounds containing nitrogen like amino acids, poly-APS also stimulates the fruiting by serving as a nutrient supplement because of the presence of large amounts of nitrogen [34]. Inoculation of Pleurotus ostreatus strain Plo5 mycelium on nutrient plates containing osrteolysin inhibits the growth of mycelia in a concentration-dependent way. After seven days of inoculation, the growth of mycelia was prevented by nearly 13,60 , and $85 \%$ on plates containing 10,100 , and $250 \mathrm{ng} / \mathrm{mm}^{2}$ of ostreolysin, respectively. It was shown that primordial formation in control plates inoculated with Pleurotus ostreatus (strain Plo5) got initiated at the $24^{\text {th }}$ day after the treatment with different concentrations of BSA or only with Tris$\mathrm{HCl}$ buffer. In this case, only one primordium (on a control plate containing $250 \mathrm{ng} / \mathrm{mm}^{2}$ of BSA) got developed into a fruiting body. On plates treated with ostreolysin, aggregation of hyphae and primordial formation occurred on $14 \mathrm{~d}$ after induction in contrast to the control. And, in these plates, young fruiting bodies were formed on the 22nd day [35].

\section{Physiological effect on fruiting body development}

Formation of the fruiting body is affected by the physiological and mycelial nutritional condition $[13,36]$. Compost made from straw, chicken or horse manure, calcium, sulfate (gypsum), water and few other nutritional supplements is a low-cost cultural substrate for Agaricus bisporus and few other saprophytic basidiomycetes. Straw present in compost acts as a carbon source and manure acts as a nitrogen source. For the growth of Pleurotus, Volvariella and Flammulina, non-composted, chopped and water-soaked straw is used. Production of the fruiting body of Agaricus is increased by 25$50 \%$ when supplemented with compost containing protein-rich minerals like soybean meal [26]. Artificial media containing glucose and malt extract are adequate for the fruiting of $C$. cinereus and $S$. commune [37]. It is essential to maintain stability between carbon and nitrogen sources for fruiting body induction [36]. When the carbon, nitrogen ratio gets very high, then knots in hyphae in $C$. cinereus develop simply into sclerotia, a multicellular structure [38]. For the fruiting of $A$. bisporus the favorable $\mathrm{C} / \mathrm{N}$ ratio in compost lies between 80:1 and 10:1 [12]. Basidiomycetes usually use lignocellulosic substrate as a carbon source. In order to degrade the lignocellulosic substrate, i.e. peroxidase and laccases for the breakdown of lignin degradation and several types of glucanases, cellulases and xylanases for the breakdown of cellulose and hemicellulose, the fungi during their vegetative growth produces a broad range of enzymes [26,39]. During fruiting, a connection is indicated between change in enzyme activities and regulation of development of the fruiting body. Like in case of A. bisporus and $L$. edodes, just before fruiting body initiation, laccase activity is maximum, but it rapidly decreases with aggregate formation. During fruiting body development, cellulase activity is higher $[25,26,40]$.

For cultivation of mushroom substrate used normally contain organic nitrogen source, but low free ammonium, as the excess of it can hinder the fruiting of the organisms. It has been shown that for amino acids and $\mathrm{NH}_{4}{ }^{+}$in $\mathrm{A}$. bisporus, various high-affinity transport systems are present. It was found that when $A$. bisporus, $C$. cinereus and $V$. volvacea (paddy straw mushroom) are grown on protein as a carbon source, excess nitrogen produced from the breakdown of protein is discharged as ammonium ion into the medium $[26,38]$.

There is an increased production of the fruiting body of the mushroom, Pleurotus ostreatus, when it is cultivated in the solid state on media containing sugarcane bagasse-wheat bran (5:1) with veratryl alcohol. It is clear from the result that a new physiological function is shown by veratryl alcohol in stimulation of fruiting body development. During the stage of mycelial growth, laccase production is also activated by veratryl alcohol. There are evidences for the involvement of laccase in the physiological development of the fruiting body [41].

It has been found that in $C$. cinereus due to the enhanced adenylate cyclase activity cAMP levels rises with the light-induced initial formation. Also, the fruiting response is associated with the increased cAMP-protein kinase activity. There is a decrease in cAMP level again with the proceeding development of primordia. For cAMP production, protein activity is regulated at the posttranslational level as it has been shown by the transcript study of the gene cac i.e. cloned adenylate cyclase $[15,38]$.

It has been found in the mycelium that relocation of nutrients occurs to hold one specific or a few selected primordia. It has been observed in C. cinereus, that there is a breakdown of storage polysaccharides (glycogen) in the substrate mycelium during the transition from vegetative growth to fruiting body development. Instead, in the young primordium glycogen gets collected first in the base of the stem, from where it subsequently disappears and during further development gets translocated to the tissues of the gills. In karyogamy, a gathering of glycogen in the tissues of the gills is maximum in the early phases of fruiting body maturation but accumulates get vanished in the developed fruiting bodies. Transfer of glycogen is escorted by the increased activities of glycogen synthase and glycogen phosphorylase. Undoubtedly, metabolic energy is provided by it for mushroom development. The metabolic energy is predicted to be 25J per fruiting body [38].

\section{CONCLUSION}

There are different environmental factors affecting the fruiting body development of mushrooms. The positioning of stipe and pileus of oyster mushroom is controlled by the phototropic responses. Also, $\mathrm{CO}_{2}$ concentration has an intense impact on sporophore development. In, A. bisporus, the concentration of $\mathrm{CO}_{2}$ above $1-5 \%$ activate stipe elongation but prevents cap expansion. Temperature affects sporophore development too. In C. cinereus, the optimum temperature for mycelia growth is about $37^{\circ} \mathrm{C}$. It has been found that in subtropical and tropical regions two species of oyster mushroom, P. ostreatus and $P$. cystidiosus grows comparatively better in summer and autumn season. Microorganisms like Pseudomonas influences fruiting in many Agaricus strains. Inoculation of mycelium of $P$. ostreatus in the growth medium containing poly-APS the formation of primordia increased. It has been found that for induction of fruiting body, it is essential to maintain stability between carbon and nitrogen sources. It has also been found that there is an increase in the production of the fruiting body of the fungus when $P$. ostreatus are grown in solid state in media containing sugarcane bagasse wheat bran (5:1) with veratryl alcohol. 
It has been shown in $C$. cinereus that a higher activity of cAMP-protein kinase is associated with the fruiting response. Also, there is a breakdown of storage polysaccharide (glycogen) in the substrate mycelium during the transition from vegetative growth to fruiting body development in $C$. cinereus.

\section{ACKNOWLEDGEMENT}

The authors are thankful to Centre of Excellence (COE) TEQIP-II (Grant no.-NPIU/TEQIP II/FIN/31/158) for financial support and Dept. of Bioengineering, Birla Institute of Technology for providing $R$ and $\mathrm{D}$ facilities.

\section{CONFLICTS OF INTERESTS}

The authors certify that there is no conflict of interest with any financial organization regarding the material discussed in the manuscript.

\section{REFERENCES}

1. Gaston KJ. Global patterns in biodiversity. Nature 2000;405:220-7.

2. Carlilie ML, Watkinson SC, Gooday GW. The fungi. Academic Press, UK; 2001.

3. Chang ST, Miles PG. Mushroom biology-a new medicine. Mycologist 1992;6:64-5.

4. Adriano FT, Cruz RA. The chemical composition of Philippines mushroom. Philipp J Agric Food Chem 1993;4:1-11.

5. Andrae T, Borcher S, Stern JS, Hackman RM, Keen CL, Gershwin $\mathrm{ME}$, et al. Mushrooms, tumors and immunity. Proc Soc Exp Biol Med 1999;221:281-93.

6. FAO. Food composition for use in East Asia Food Policy and Nutrition Division. Food Agriculture, U. N Rome; 1972. Available from: www.fao.org/docrep/003/x6878e/ X6878E33.htm\#grp2. [Last accessed on 10 Apr 2017]

7. Tripathy SS, Rajoriya A, Mahapatra A, Gupta N. Biochemical and antioxidant properties of wild edible mushrooms used for food by tribal of eastern India. Int J Pharm Pharm Sci 2016;8:194-9.

8. Daba AS, Ezeronye OU. Anti-cancer effect of polysaccharides isolated from higher basidiomycetes mushrooms. Afr J Biotechnol 2003;2:672-8.

9. Szeto M. Coriolus versicolor extracts: relevance in cancer management. Curr Oncol 2007;14:41-7.

10. Maji P, Chatterjee R, Choudhury BP, Chatterji U, Ganguly J. Enhanced p53-dependent growth inhibition of human glioblastoma cells by combinatorial treatment of temozolomide and novel purified natural carbohydrate of Pleurotus florida. Int J Pharm Pharm Sci 2017;9:189-93.

11. Rohan. Mushroom Market worth $\$ 50,034.12$ million by; 2019. Available from:www.marketsandmarkets.com/PressReleases/ mushroom.asp. [Last accessed on 19 Jun 2017]

12. Scrase RJ, Elliott TJ. Biology and technology of mushroom culture. Microbiol Fermented Food 1998;2:543-84.

13. Flegg PB, Wood DA. Growth and fruiting. In: Flegg PB, Spencer DM, Wood DA. The biology and technology of the cultivated mushroom. Wiley, London; 1985. p. 141-77.

14. Williams MAJ, Beckett A, Read ND. Ultrastructural aspects of fruit body differentiation in Flamminula velutipes. In: Moore D, Casselton LA, Wood DA, Frankland JC. Eds. Developmental biology of higher fungi. Cambridge University Press, Cambridge; 1985. p. 429-50.

15. Kues U. Life history and developmental processes in the basidiomycete Coprinus cinereus. Microbiol Mol Biol Rev 2000;64:316-53.

16. Danell E, Camacho FJ. Successful cultivation of the golden chanterelle. Nature 1997;385:303.

17. Iwase K. Cultivation of mycorrhizal mushrooms. Food Rev Int 1997;13:431-42.

18. Eastwood DC, Herman B, Noble R, Dobrovin-Pemington A, Sreenivasaprasad S, Burton KS. Environmental regulation of reproductive phage change in Agaricus bisporus by 1-octen-3ol, temperature and $\mathrm{CO}_{2}$. Fungal Gen Biol 2013;55:54-6.

19. Kues U, Liu Y. Fruiting body production in basidiomycetes. Appl Microbiol Biotechnol 2000;54:141-52.
20. Chang ST, Miles PG. Mushrooms-cultivation, nutritional value, medical effect, and environmental impact. Boca Raton: CRC Press; 2004. p. 2-3,19,68-9,95,136-37,255,315-19,426.

21. Kinugawa K. Physiology and the breeding of Flammulina velutipes. Genetics and breeding of edible mushrooms. Gordan Breach Sci 1993. p. 87-109.

22. Wessels JGH. Fruiting in higher fungi. Adv Microb Physiol 1993;34:147-202.

23. Milkwood. Mushrooms Growers Handbook 1: Oyster mushroom cultivation, San Francisco CA, www.mushworld.com. Available from: www.mushworld.com. 2004. [Last accessed on 19 Jun 2017]

24. Hoa HT, Wang C. The effects of temperature and nutritional conditions on mycelium growth of two oyster mushrooms (Pleurotus ostreatus and Pleurotus cystidiosus). Mycobiology 2015;43:14-3.

25. Ohga S. Effect of water potential on fruit body formation of Lentinula edodes in the sawdust based substrate. JWood Sci 1999;45:337-42.

26. De Groot PWJ, Visser J, Van Griensven LJLD, Schapp PJ. Biochemical and molecular aspects of growth and fruiting of the edible mushroom Agaricus bisporus. Mycol Res 1998;102:1297-308.

27. Frey-Klett P, Burlinson P, Deveau A, Barret M, Tarkka M, Sarniguet A. Bacterial-fungal interactions: hyphens between agricultural, clinical, environmental, and food microbiologists. Microbiol Mol Biol Rev 2011;75:583-609.

28. Deveau A, Brule C, Palin B, Champmartin D, Rubini P, Garbaye J, et al. Role of fungal trehalose and bacterial thiamine in the improved survival and growth of the ectomycorrhizal fungus Laccaria bicolor S238N and the helper bacterium Pseudomonas fluorescens BBc6R8. Environ Microbiol 2010;2:560-8.

29. Grewal S, Rainey P. Phenotypic variation of Pseudomonas putida and $P$. tolaasii affects the chemotactic response to Agaricus bisporus mycelial exudates. J Gen Microbiol 1991;137:2761-8.

30. Sepcic K, Batista U, Vacelet J, Macek P, Turk T. Biological activities of aqueous extracts from marine sponges and cytotoxic effect of 3-alkyl pyridinium polymers from Reneira sarai. Comp Biochem Physiol 1997;117:47-3.

31. Malovrh P, Sepcic K, Turk T, Macek P. Characterisation of haemolytic activity of 3-alkylpyridinium polymers from the marine sponge Reniera sarai. Comp Biochem Physiol 1999;124C:221-6.

32. Sepcic K, Marcel V, Klaebe A, Turk T, Suput D, Fournier D. Inhibition of acetylcholinesterase by an alkyl pyridinium polymer from the marine sponge, Reniera sarai. Biochim Biophysica Acta 1998;1387:217-25.

33. Chelossi E, Mancini I, Sepcic C, Turk T, Faimali M. Comparative antibacterial activity of polymeric 3-alkylpyridinium salts isolated from the Mediterranean sponge Reniera sarai and their synthetic analogues. Biomol Eng 2006;23:317-23.

34. Eger G. The action of light and other factors on sporophore initiation in Pleurotus ostreatus. Mush Sci 1976;9:575-83.

35. Berne S, Pohleven J, Vidic I, Rebolj K, Pohleven F, Turk T, et al. Ostreolysin enhances fruiting initiation in the oyster mushroom (Pleurotus ostreatus). Mycol Res 2007;111:1431-6.

36. Madelin MF. Studies on the nutrition of Coprinus lagopus, especially as affecting fruiting. Ann Bot 1956;20:467-80.

37. Walser PJ, Hollenstein M, Klaus MJ, Kues U. Genetic analysis of basidiomycete fungi. Molecular and cell biology of filamentous fungi: a practical approach. Oxford University Press; 2001.

38. Moore D. Fungal morphogenesis. Cambridge University Press: New York; 1998.

39. Stoop JMH, Mooibroek H. Advances in genetic analysis and biotechnology of the cultivated button mushroom, Agaricus bisporus. Appl Microbiol Biotechnol 1999;52:474-83.

40. Ohga S. Comparison of extracellular enzyme activities among different strains of Lentinus edodes grown on sawdust based cultures in relationship to their fruiting abilities. Mokuzai Gakkaishi 1992;38:310-6.

41. Suguimoto HH, Barbosa AM, Dekker RF, Castro-Gomez RJ. Veratryl alcohol stimulates fruiting body formation in the oyster mushroom, Pleurotus ostreatus FEMS. Microbiol Lett 2001;194:235-8.

\section{How to cite this article}

- $\quad$ Foziya Khan. Effect of physiochemical factors on fruiting body formation in mushroom. Int J Pharm Pharm Sci 2017;9(10):33-36. 